August 1979

\title{
A Classification Scheme For The Common Passive and Hybrid Heating and Cooling Systems
}

Michael J. Holtz

Wayne Place

Ronald Kammerud
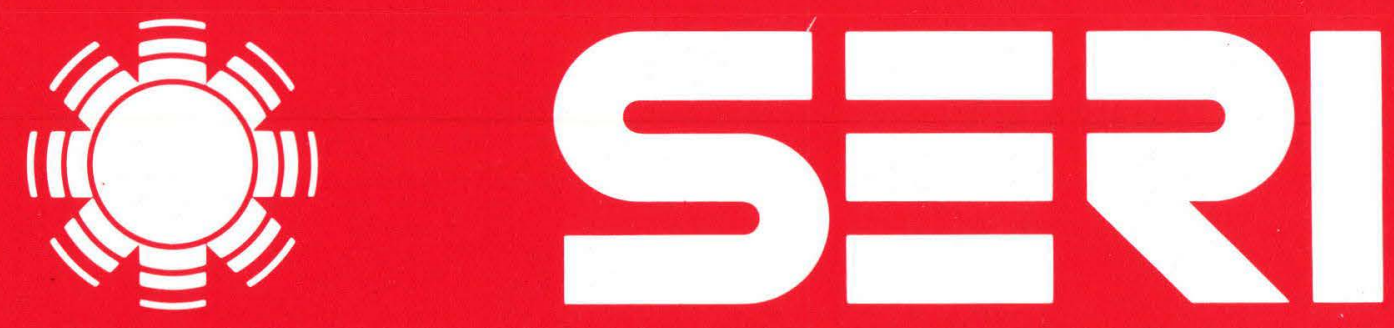

Solar Energy Research Institute

A Division of Midwest Research Institute

1536 Cole Boulevard

Golden, Colorado 80401

Operated for the U.S. Department of Energy under Contract No. EG-77-C-01-4042

\section{SERI/TP-63-218}

c.2 


\section{NOTICE}

This report was prepared as an account of work sponsored by an agency of the United States Government. Neither the United States nor any agency thereof, nor any of their employees, makes any warranty, expressed or implied, or assumes any legal liability or responsibility for any third party's use or the results of such use of any information, apparatus, product, or process disclosed in this report, or represents that its use by such third party would not infringe privately owned rights. 


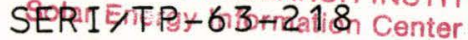

UC CATEGORY: UC-59A

\section{OCT 91979}

GOLDEN, COLORADO 80401

A CLASSIFICATION SCHEME FOR THE COMMON PASSIVE AND HYBRID HEATING AND COOLING SYSTEMS

MICHAEL J. HOLTZ

WAYNE PLACE

RONALD KAMMERUD

SOLAA ENERGY RESEARCH INSTITUTE

Solar Energy Information Conter

\section{AUG 131979}

AUGUST 1979

GOLDEN, COLORADO 80401

PREPARED UNDER TASK NO. 6324.10

\section{Solar Energy Research Institute}

1536 Cole Boulevard

Golden, Colorado 80401

A Division of Midwest Research Institute

Prepared for the

U.S. Department of Energy

Contract No. EG. $77 \cdot C \cdot 01 \cdot 4042$ 


\section{FOREWORD}

This technical paper was written as a result of the preparation of the U.S. Department of Energy's National Program Plan for Passive/Hybrid Solar Heating and Cooling. Responsibility for the preparation of this plan has been jointly shared by the Passive Solar Group at the Lawrence Berkeley Laboratory and the Passive Technology Branch at the Solar Energy Research Institute. The paper was written as a part of Task 6324 to clarify numerous definitional problems surrounding passive systems, and to present a general framework for thinking about passive systems and a systematic method for classifying the more common configurations.

The authors of this technical paper are Wayne Place and Ronald Kammerud of the Lawrence Berkeley Laboratory and Michael Holtz of the Solar Energy Research Institute. This work has been supported by the Solar Heating and Cooling Research and Development Branch, Office of Conservation and Solar Applications, U.S. Department of Energy.

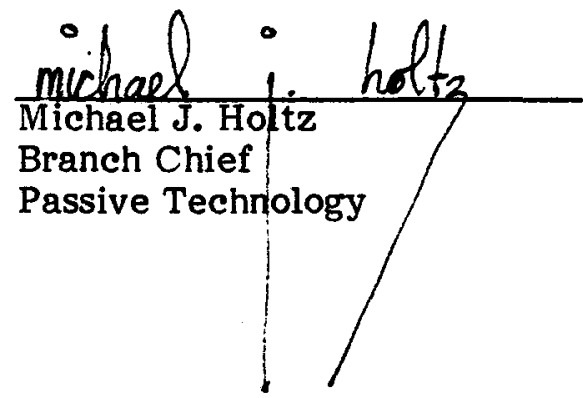




\section{ABSTRACT}

A systematic nomenclature and classification scheme is proposed for passive space heating and cooling systems. It is based on the mode of energy transport to and from the space and the environmental resource from which the energy is received or to which it is discharged. A number of passive and hybrid space heating and cooling systems are characterized.

\section{INTRODUCTION}

A passive building design attempts, within economic constraints, to maximize the benefits of environmental resources and to minimize dependence on fossil fuels and mechanical equipment. This is accomplished by selectively coupling parts of the building to the environment most appropriate to the energy transfer desired at any given time. In contrast to traditional conservation, which stresses isolation from the environment, passive heating and cooling represent an assertive attempt to use the environment through judicious interaction.

Passive solar heating systems use elements of the building to collect, store, and distribute energy. Passive cooling also uses elements of the building to store and distribute energy and, when prevailing conditions are favorable, to discharge heat to the cooler parts of the environment (sky, atmosphere, ground). In all cases, energy transfers to, from, and within the building rely primarily on natural processes, i.e., conduction, convection, and radiation, with minimal dependence on mechanical equipment such as fans, pumps, and compressors. Mechanical equipment can be used effectively to augment natural energy flows when the capital cost and operating energy are justified by the improved system performance.

Since the collection, discharge, storage, and distribution of energy is generally accomplished bv the architectural elements and features of the building, the passive system components are not easily distinguishable from the remainder of the structure. Because of the integral nature of passive systems and the myriad of possible configurations, considerable confusion has existed concerning how to define and classify them. This paper presents a general framework for thinking about passive systems and a systematic method for defining and classifying the more common configurations.

\section{GENERAL DEFINITIONS}

A solar space heating system contains the following elements:

o a space (or, more specificallv, contents) to be heated,

o a collector where solar radiation is admitted into the system and converted to heat by an absorber (this may be nothing more than a surface of the normal building envelope), and

- thermal storage (this may be nothing more than the normal thermal capacity of the building mass).

Possible energy exchanges exist between:

o collector and storage,

o collector and space, and

o storage and space.

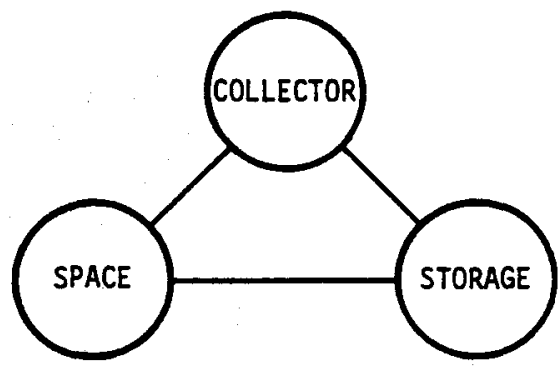

A space cooling system contains the following elements:

o a space (or, more specifically, contents) to be cooled,

o an environmental sink (sky, atmosphere, or ground) to which heat is discharged, and

- thermal storage (this may be nothing more than the normal thermal capacity of the building mass). 
Possible energy exchanges exist between:

- sink and storage,

o sink and space, and

o storage and space.

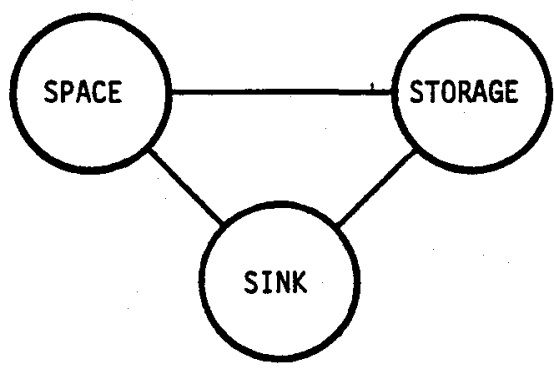

In a given heating or cooling system, some of the exchanges may not exist, or at least they may be insignificant.

The energy exchanges fall into two categories:

- forced (using fans, pumps, and compressors), and

- natural (involving conduction, convection, and radiation).

The distinction made is based on the driving influence causing the energy flow, and not on the degree of regulation. The term "natural energy flow" is not synonymous with "unregulated energy flow." Natural energy flow can, in fact, be highly regulated by mechanically-actuated controls, such as dampers or moving insulation. The point is that the flow motivation derives from non-mechanical sources.

If all of the significant exchanges linking the three elements of a heating or cooling system involve forced flow, the system is classified as active.

If all of the significant exchanges linking the three elements of a heating or cooling system involve purely natural flow, the system is classified as passive.

If some of the significant exchanges linking the three elements of a heating or cooling system involve predominantly natural flow, but the system also incorporates mechanical devices to move energy, then the system is classified as hybrid.

\section{HEATING}

There are two particularly important factors that must be accounted for in any scheme for characterizing passive solar heating systems:

(1) the characteristics of the collection aperture:

o orientation with respect to south and vertical, and

o location relative to the rest of the building structure).

(2) The method of delivering energy to the conditioned space:

o energy mechanism(s), and

o inherent degree of thermal control.

\subsection{Collection Aperture Characteristics}

In the temperate zones of the earth's northern hemisphere, the winter sun rises south of east and remains generally low in the southern sky until it sets south of west. In contrast, the summer sun rises north of east and soars to high altitude angles before setting north of west.* Consesquently, south-facing vertical glazing accepts direct-beam winter sun at favorable angles of incidence throughout the day (shown on the following page).

On the other hand, south-facing vertical glazing is not exposed to direct-beam summer sun dur-

*For a more detailed discussion of sun angles see "The Solar Resource: Motion and Amplitude," by Wayne Place, p. 769 of the Proceedings of the Second National Passive Solar Conference. 


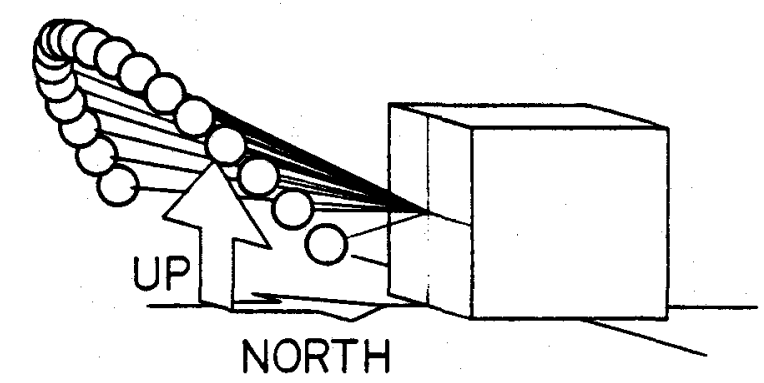

WINTER SUN ANGLES ON
SOUTH-FACING SURFACE

ing a substantial portion of the day, and during those hours that exposure does occur, the angle of incidence is unfavorable to penetration (shown below).

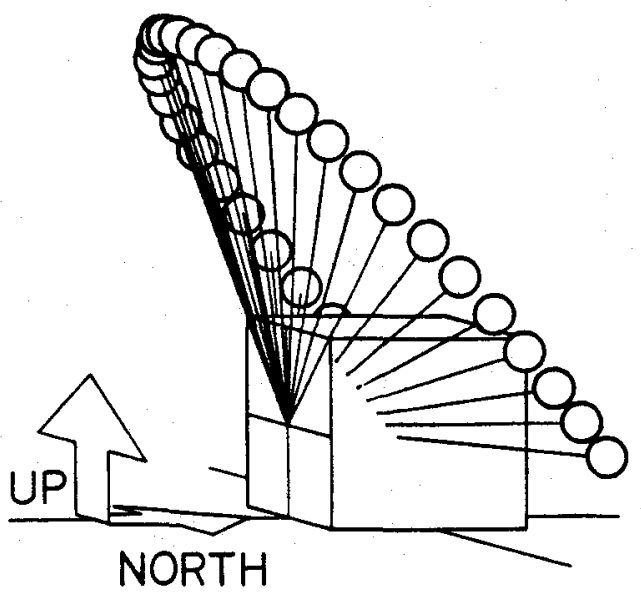

\section{SUMMER SUN ANGLES ON SOUTH-FACING SURFACE}

Furthermore, modest overhangs can completely eliminate all exposure to direct-beam summer sun. In this sense, south-facing vertical glazing may represent the ultimate passive technique. Within the building's environment, the sun's motion is the major control of the building's thermal environment.

Going to the opposite extreme, horizontal glazing receives modest amounts of direct-beam winter sun, generally at unfavorable angles of incidence, and is subjected to severe directbeam summer sun, generally at angles corre-
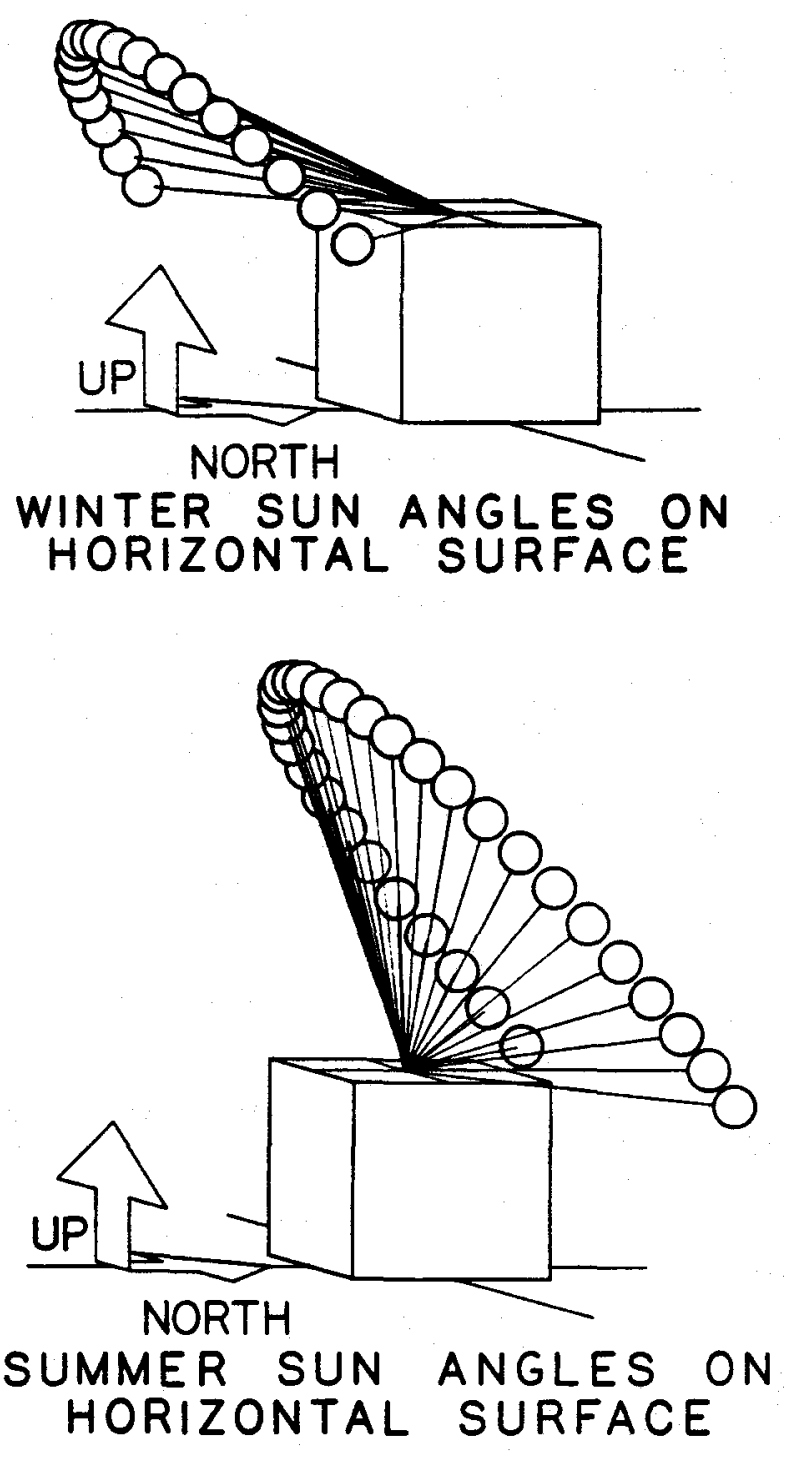

sponding to high glazing transmissivity (refer to the above diagrams).

By itself, horizontal glazing responds to the sun's motion in a manner which amplifies the seasonal temperature variation. Evidently some special method must be used to regulate the flow of energy through the aperture (e.g., movable insulation). Such systems will be more complicated than those employing simple southfacing vertical glazing, but the added complexity may be justified in terms of greater system control or cooling benefits.

Also of importance is the location of the aper- 
ture relative to the rest of the building structure. In the common passive solar heating systems the three possible locations are the south wall, the roof, and somewhere remote from the building envelope proper. South wall heating systems have the advantages of simplicity and economy. Roof heating systems work well in situations where land constraints limit south wall exposure or restrict proper orientation of the building. They also have the advantage of treating all zones equally. Remote heating systems can be designed to have simple controls which limit unwanted gains or losses from the building. They also have the advantage of providing additional collection area to supplement energy collected through the building envelope proper.

There exists a limited number of energy advantageous combinations of aperture orientation location:

There exists a limited number of energy advantageous combinations of aperture orientation and location:

- A south aperture in the building consists of vertical glazing elements in the south wall. Such an aperture accepts sunlight predominantly from the southern part of the sky (winter sun).

- A shaded roof aperture in the building consists of vertical glazing elements and sloping opaque elements on the roof. Such an aperture accepts sunlight predominantly from the southern part of the sky (winter sun).

- A roof aperture in the building consists of horizontal glazing elements on the roof. Unless controlled by special methods, e.g., moving insulation, such an aperture accepts sunlight predominantly from the upward part of the sky (summer sun).

o A remote aperture, i.e., one that is not part of the building envelope proper, can be set at anv angle to accept sunlight from any part of the sky.

\subsection{Energy Delivery Method}

The manner in which energy is delivered to the conditioned space has a profound impact on the degree of thermal uniformity that can be imposed. Selection of the most cost-effective system for any application is strongly influenced by the severity of the thermal requirements. There exist three broad categories of passive solar heating systems based on the energy delivery to the space:

- For direct heating, sunlight is admitted directly to the space, where it is converted to heat by absorption on the interior surfaces and contents of the space (people, furnishings, plants, etc.). The contents or surfaces of the space must be exposed to sunlight in order for the system to collect energy. The air temperature in the space "floats" with the absorbing surfaces and/or the storage.

o For indirect heating, sunlight is converted to heat by absorption on a surface external to the space. Contents of the space are not exposed to direct sunlight. The air temperature in the space "floats" with the absorber and/or the storage.

o For isolated heating, sunlight is converted to heat by absorption on a surface external to the space. Contents of the space are not exposed to direct sunlight. The air temperature in the space can be regulated independently of the absorber and storage.

The following matrix indicates the level of control of the thermal environment for each type of system (direct, indirect, or isolated) in terms of sunlight exposure and thermal coupling of the space to absorbing surfaces or storage mass:

\begin{tabular}{l|c|c|c|}
\cline { 2 - 4 } & Direct & Indirect & Isolated \\
\hline $\begin{array}{l}\text { Sunlight enters } \\
\text { space }\end{array}$ & Yes & No & No \\
\hline $\begin{array}{l}\text { Air temp. floats } \\
\text { with absorber } \\
\text { and/or storage }\end{array}$ & Yes & Yes & No \\
\hline
\end{tabular}


The choice of a direct, indirect, or isolated system is strongly influenced by the desired degree of thermal uniformity or control. Where very fine thermal regulation is stipulated, isolated systems will generally be preferred. Isolated heating systems can be completely passive, but in terms of control over the thermal environment, they resemble active systems; that is, the system interaction with the space can be fully regulated and turned "on" and "off." If sizable thermal fluctuation can be tolerated and minimum auxiliary energy use is desired, direct gain or indirect gain systems will generally be preferred.

Given these basic definitions, we can classify the common passive heating systems in terms of the following matrix:

\begin{tabular}{r|c|c|c|}
\cline { 2 - 4 } & Direct & Indirect & Isolated \\
\hline South Aperture & $\bullet$ & $\bullet$ & $\bullet$ \\
\hline $\begin{array}{r}\text { Shaded Roof Aper- } \\
\text { ture }\end{array}$ & $\bullet$ & $\bullet$ & $\bullet$ \\
\hline Roof Aperture & $\bullet$ & $\bullet$ & $\bullet$ \\
\hline Remote & & $\bullet$ & $\bullet$ \\
\hline
\end{tabular}

Various combinations of aperture location and mechanisms for transferring energy to the occupied space are shown schematically in Fig. 1.

The configurations shown include the currently most common passive heating systems and provide a representative sampling of less common systems that may have equal potential. These combinations by no means exhaust the list of possibilities. Additionally, this figure introduces a general nomenclature for passive system description.

Combinations of the three systems are of considerable importance. For example, direct gain openings can be placed in a storage wall or an isolated storage wall. The openings can be sized to account for daytime winter heating requirements and for year-round illumination. Another example of combined direct and indirect heating is the use of clear or translucent water storage containers placed in the aperture. Some light is absorbed and stored in the water and some light is transmitted into the space to heat and illuminate.

There exists an assortment of multi-zone single-story schemes with solar heating applied to each zone. Some of the more interesting twozone examples are illustrated in Fig. 2. These systems have the quality that each zone can be individually designed to meet the particular thermal illumination requirements dictated by the intended function of the space. The extension of these schemes to single-story buildings of three or more zones is obvious.

A more difficult classification problem is posed by large, multi-story buildings. Asymmetric solar excitations, such as occur in south aperture systems, naturally drive a north-south zone separation. Multi-story commercial structures will clearly be north-south zoned in most cases and the functional utilization of the space must be planned in accordance. However, in order to fully implement passive design concepts and maintain flexibility in space utilization, methods of enhancing or suppressing the natural zone structure of the space must be developed. In some cases this can be accomplished by purely passive means; in other cases hybrid schemes involving mechanically-assisted heat transfer will be more appropriate. The problem of energy transport becomes very critical in largescale buildings, particularly for high-occupancy commercial applications or situations where industrial processes require high ventilation rates.

The most appropriate roles for passive solar within more general energy management schemes are not presently identified, and the identification of those roles will require a substantial level of effort in innovative concept generation as well as rigorous technical evaluation. Until these roles are identified and the resulting systems thoroughly investigated, any attempt to develop a comprehensive classification scheme for large-scale buildings would be premature.

\section{COOLING}

Passive cooling involves the discharge of energy by selective coupling of the system to the cooler parts of the environment. If the environ- 
mental conditions are correct, this energy flow will occur by natural means. Possible environmental sinks for heat from the system are the sky, atmosphere, and ground.

In sky cooling, radiation from the system passes through the atmosphere and dissipates into outer space. Environmentally, it is the purest mode of cooling, since none of the energy discharged from the system appears in the local microclimate. Radiative sky cooling works well in environments with clear skies, and has the potential to cool the system below the ambient air temperature. The primary limit to this cooling mechanism is convective and radiative heat gain from the surrounding atmosphere.

Energy from the system can also be discharged directly to the atmosphere during those times when the ambient air conditions are favorable to such an exchange. Heat can be dissipated by raising the sensible heat energy of the surrounding air (e.g., night air cooling) or by raising its latent heat energy (e.g., evaporative cooling). In either case, the energy transfer can be greatly enhanced by increased air movement. The driving force for this movement can come from wind, fans, or special convective drive mechanisms. In dry environments, evaporative cooling has the potential, like radiative sky cooling, to reduce the system temperature below the ambient air temperature. Evaporative cooling has the disadvantage of expending water, a commodity which may be in short supply in the climates where evaporative cooling is most effective.

Because of the great thermal mass of the earth, ground temperatures during the summer will normally be several degrees below the average ambient air temperature. Unlike evaporative or radiative sky cooling, which require special climatic conditions such as dry air or clear skies, ground cooling can be used to displace a substantial fraction of the normal cooling load, even in humid, overcast environments. However, dehumidification by mechanical means may still be required.

The following table summarizes the environmental sinks, along with the primary mecha- nisms involved in the energy transfer:

\begin{tabular}{|l|l|}
\hline \multicolumn{1}{|c|}{ Sink } & $\begin{array}{c}\text { Primary Energy } \\
\text { Transfer Mechanism }\end{array}$ \\
\hline $\begin{array}{l}\text { Sky } \\
\text { Atmosphere } \\
\text { Ground }\end{array}$ & $\begin{array}{l}\text { Radiation } \\
\text { Convection* } \\
\text { Conduction }\end{array}$ \\
\hline
\end{tabular}

*Includes evaporation.

In analogy to heating systems, there are direct, indirect, and isolated cooling processes:

- Direct cooling occurs when the interior surfaces and contents of the space are exposed directly to the environmental energy $\operatorname{sink}(\mathrm{s})$.

- Indirect cooling occurs when the space is cooled by uncontrolled radiation to storage (or some exchange surface) that is in turn cooled by exposure to the environmental energy sink(s).

- Isolated cooling occurs when the space is cooled by controlled fluid or radiative transfer to storage (or some exchange surface) that is in turn cooled by exposure to the environmental energy sink(s).

As in the case of heating, we can classify passive cooling systems in terms of a matrix:

\begin{tabular}{l|c|c|c|}
\cline { 2 - 4 } & Direct & Indirect & Isolated \\
\hline Sky & $\bullet$ & $\bullet$ & $\bullet$ \\
\hline Atmosphere & $\bullet$ & $\bullet$ & $\bullet$ \\
\hline Ground & $\bullet$ & & $\bullet$ \\
\hline
\end{tabular}

A representative sample of combinations of the environmental thermal energy sinks and mechanism for transferring energy to the occupied space are shown in Fig. 3. The configurations shown include the currently most common passive cooling systems and a representative sampling of less common systems that may have equal potential. These combinations by no means exhaust the list of possibilities. The figure introduces a general nomenclature for pas- 
sive cooling system description.

Emphasis has been placed on systems whose elements can serve both a heating and cooling function, and whenever possible the heating system nomenclature is retained. For example, a Storage Roof cooling system uses all the same elements as a Storage Roof heating system, except that the air space, which may be necessary to reduce winter losses, must be eliminated for summer cooling. Also listed in the table are several promising cooling schemes whose elements do not serve a heating function. In general, passive heating is considerably more advanced than passive cooling.

For many advanced heating systems there does not exist a well-defined cooling system employing some or all of the same elements. For example, there are several well-understood Stor- age Wall heating systems, but no well-defined schemes for using that mass with comparable effectiveness in the cooling mode. Despite the lack of well-defined concepts, the idea of using storage walls in the cooling mode appears to merit further consideration.

As in the case of passive space heating, roles for passive cooling in more general energy management schemes for large-scale commercial and industrial buildings remain to be identified and evaluated.

\section{ACKNOWLEDGEMENT}

This work has been supported by the Solar Heating and Cooling Research and Development Branch, Office of Conservation and Solar Applications, U.S. Department of Energy. 


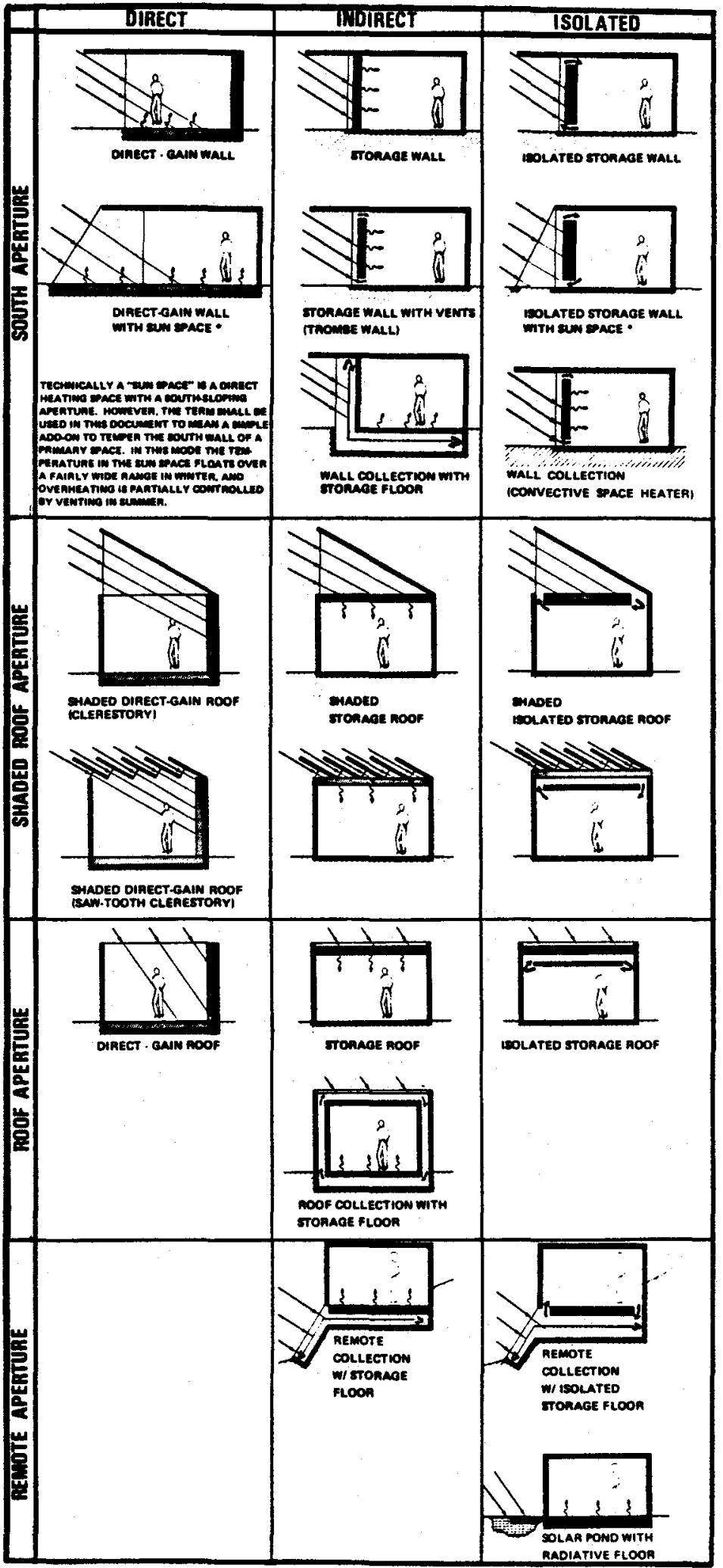

FIGURE I: EXAMPLES OF PASSIVE SOLAR HEATING SYSTEMS 

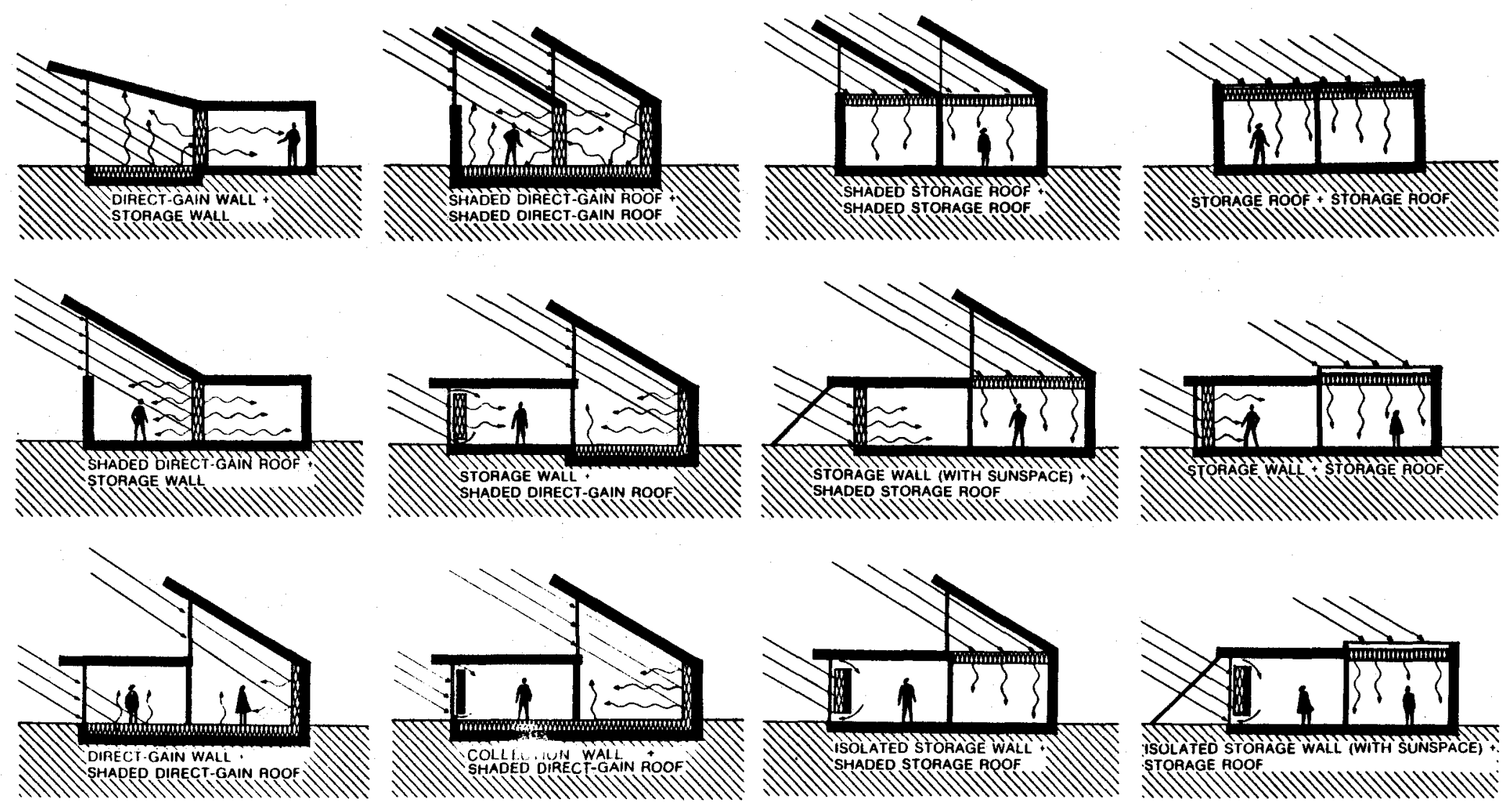

figune 2: Examples of sincle-stonr, mutti-20ne, Passive solan srstems 


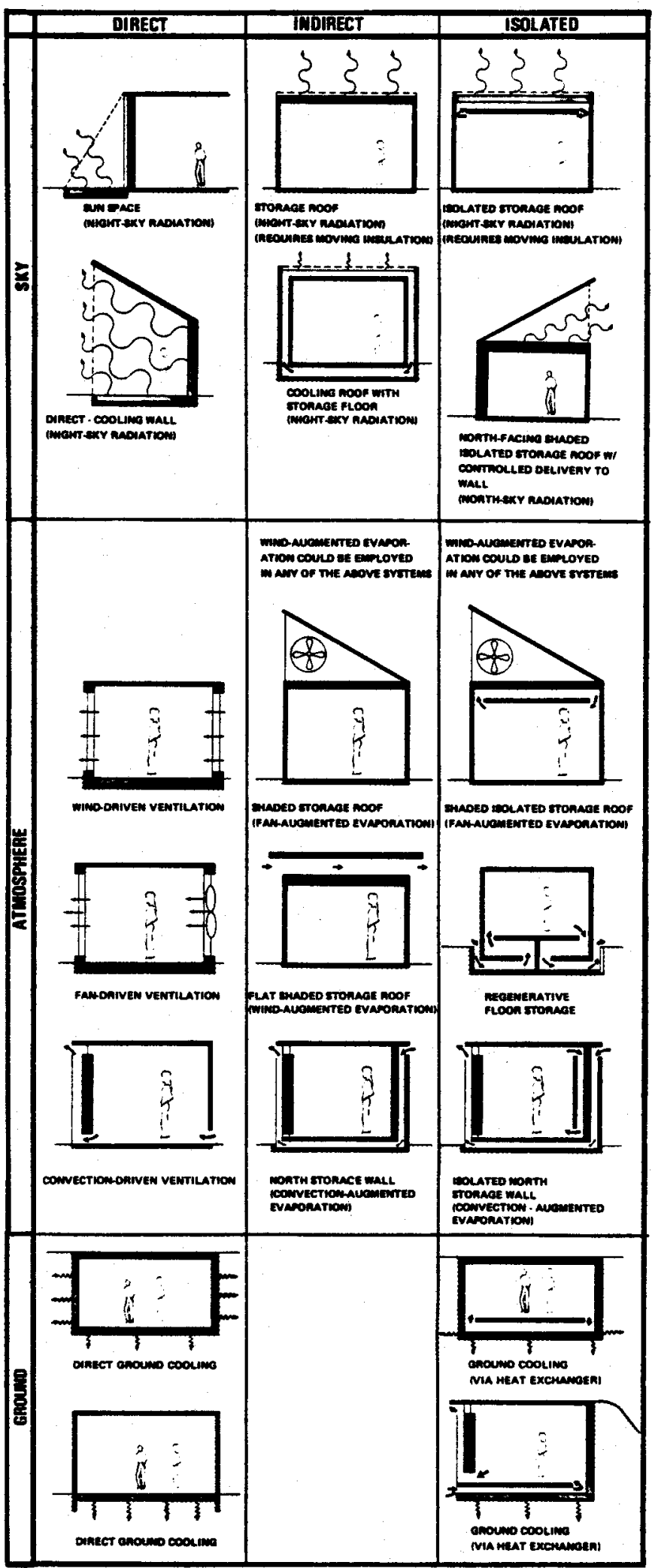

FIGURE 3: EXAMPLES OF PASSIVE SOLAR COOLING SYSTEMS 
HPE

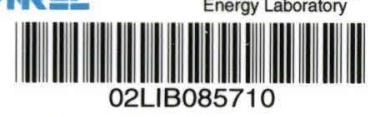

4 